\title{
Deformation partitioning during folding and transposition of quartz layers
}

\author{
L. Lagoeiro*, J. Hippertt, C. Lana \\ Departamento de Geologia, Universidade Federal de Ouro Preto, 35400-000, Ouro Preto, Minas Gerais, Brazil
}

Received 16 October 2001; accepted 24 September 2002

\begin{abstract}
Banded iron formation (BIF) from the Quadrilátero Ferrífero (southeastern Brazil) shows a compositional layering with alternating iron-rich and quartz-rich layers. This layering was intensively folded and transposed at a centimeter/millimeter scale through a component of bedding-parallel shear related to flexural slip at middle to high greenschist facies conditions (400-450 $\left.{ }^{\circ} \mathrm{C}\right)$. The microstructure and $c$-axis fabrics of normal limbs, inverted limb and hinge zones of a selected isoclinal fold were analyzed combining optical and scanning electron microscopy (SEM) and digital image analysis. In the normal limbs, recrystallized quartz grains show undulose extinction, relatively dry grain boundaries, $c$-axes at high angle to foliation and a pervasive grain shape fabric (GSF) indicating operation of crystal-plastic processes. In the inverted limb, quartz grains show more serrated and porous ("wet") grain boundaries; the GSF is similar to that of the normal limb, but $c$-axes are oriented at $90^{\circ}$ to those of the normal limb. We interpreted these characteristics as reflecting operation of solution-precipitation deformation in inverted limbs, as a consequence of grains having been rotated to an orientation that was hard to basal $\langle a\rangle$ glide, but easy to dissolution-precipitation creep. This deformation partitioning between crystal-plasticity and solution-transfer during folding/ transposition of quartz may explain the common occurrence of layered quartz rocks, where individual layers show alternating $c$ axis fabrics with opposite asymmetries but a consistent GSF orientation. Such characteristics may reflect an earlier event of pervasive folding/transposition of a preexisting layering.

(C) 2002 Elsevier Science B.V. All rights reserved.
\end{abstract}

Keywords: Deformation partitioning; c-Axis fabric; Microstructures; Dissolution-precipitation creep; Crystal-plasticity; Foliation transposition

\section{Introduction}

Deformation of crustal rocks at low metamorphic grade conditions is commonly partitioned into brittle, crystal-plastic and fluid-assisted deformation processes (e.g. FitzGerald and Stünitz, 1993) and

* Corresponding author.

E-mail address: lagoeiro@degeo.ufop.br (L. Lagoeiro). depends on factors such as the rock composition, microstructure (grain size and rock fabrics), fluid activity (integrated fluid/rock volume ratio and fluid composition) and the applied stress field. Previous research has revealed that at low temperature conditions $\left(<300{ }^{\circ} \mathrm{C}\right)$ and in the presence of an aqueous fluid phase, the activation energy for deformation of quartz via pressure solution (Robin, 1978; Rutter, 1983 ) is lower than for dislocation creep. This commonly results in dissolution-precipitation to predom- 
inate over crystal-plasticity at low metamorphic grades. This has been corroborated by a number of experimental and theoretical studies (see Shimizu, 1995 and references therein), and also by investigation of naturally deformed quartz (e.g. Hippertt, 1994; Stallard and Shelley, 1995; Takeshita and Hara, 1998). However, investigation of naturally deformed quartzites at low and intermediate greenschist facies conditions $\left(T \approx 300-400{ }^{\circ} \mathrm{C}\right)$ has shown that, under some circumstances, crystal-plasticity and dissolution-precipitation creep can be concurrent processes of quartz deformation which operate in different microdomains of the rock (e.g. Hippertt, 1994; Lagoeiro, 1999). This deformation partitioning can be related to factors such as different crystallographic orientation of grains (e.g. Tullis, 1989; Becker, 1995; den Brok, 1996) and/or an anisotropic distribution of phyllosilicate grains in the aggregate (e.g. Houseknecht, 1988).

Folded quartz layers and veins commonly show a noticeable variation of crystallographic and morphologic fabrics on a microscopic scale (e.g. Carreras et al., 1977; Stünitz, 1991). This has been interpreted as indicating operation of processes of passive folding and rotation of preexisting quartz fabrics (Carreras et al., 1977; Law, 1990), components of coaxial and simple shear deformation in different parts of folds (Stünitz, 1993) or processes of fold transposition (Hongn and Hippertt, 2001). In addition, such microstructural variations are also likely to result from different deformation mechanisms operating in different fold domains. However, the role of deformation partitioning during folding of quartzose materials has not been discussed in earlier studies. We have attempted to fill up this lacuna by investigating fabric variations in folded quartz layers from a Proterozoic banded iron formation (BIF) of the Quadrilátero Ferrífero (southeastern Brazil). We also discuss the role of crystal-plasticity and dissolution-precipitation creep as associated processes during isoclinal folding/ transposition at low metamorphic grade.

\section{Geological setting and sample location}

The tectonites selected for this study were collected in a metavolcanic-sedimentary banded iron formation of Lower Proterozoic age named Itabira Iron For- mation, whose main deformation and metamorphism is related to the $2.2-1.9$ Ga Transamazonic Orogeny (Alkmim and Marshak, 1998). Several oriented samples were collected along a cross-section in Serra da Piedade, northeastern Quadrilátero Ferrífero, Minas Gerais State, Brazil (Fig. 1). The Serra da Piedade syncline is part of a $90-\mathrm{km}$ long, $15-\mathrm{km}$ wide synclinal/homoclinal keel trending NE-SW whose flanks are steeply dipping $\left(>75^{\circ}\right)$. The syncline limbs are overturned in some localities.

Hand samples show a well-defined compositional layering characterized by alternating iron-rich and quartz-rich layers. During progressive syncline closure, this compositional layering was intensely folded and transposed at a centimeter/millimeter scale through a component of bedding-parallel shear related to flexural slip (Tanner, 1989, 1992) that caused the formation of a newly generated, discontinuous compositional banding (Hippertt and Davis, 2000). A mineral stretching lineation was developed during bedding-parallel shearing. It is defined by the alignment of tabular or platy hematite and rod-shaped quartz grains. In average, the lineation on the discontinuous compositional banding is dip-slip or slightly oblique. All shear sense indicators, i.e. sense of vergence of the microfolds and obliquity of axial planes with respect to the bedding-parallel shearing, indicate a sinistral sense of shear. The transposed folds are generally recognizable as centimeter/millimeter-sized, rootless isoclinal fold hinges whose axial planes are parallel to the compositional banding. This deformation (referred to as $D_{1}$ ) started at low to medium greenschist facies conditions of regional metamorphism and achieved its peak at upper greenschist to lower amphibolite metarmorphic facies conditions $\left(400-450{ }^{\circ} \mathrm{C}\right)$. The latter is indicated by concurrent development of garnet-staurolite-biotite paragenesis in the more pelitic lithologies. In a subsequent deformation phase $\left(\mathrm{D}_{2}\right)$, the transposed compositional layering was regionally folded and larger open folds were generated. A discrete-spaced cleavage was developed associated with these open folds. This deformation phase occurred at a significantly lower temperature $\left(<250{ }^{\circ} \mathrm{C}\right.$; Hoefs et al., 1982) and, therefore, had negligible effects on the preexisting fabrics. Thus, all fabric elements present in the iron formation rocks herein studied are attributed to $D_{1}$. $D_{1}$ deformation is believed to have occurred during the 2.2-1.9 Ga Tranzamazonian Orogeny, and $\mathrm{D}_{2}$ during 

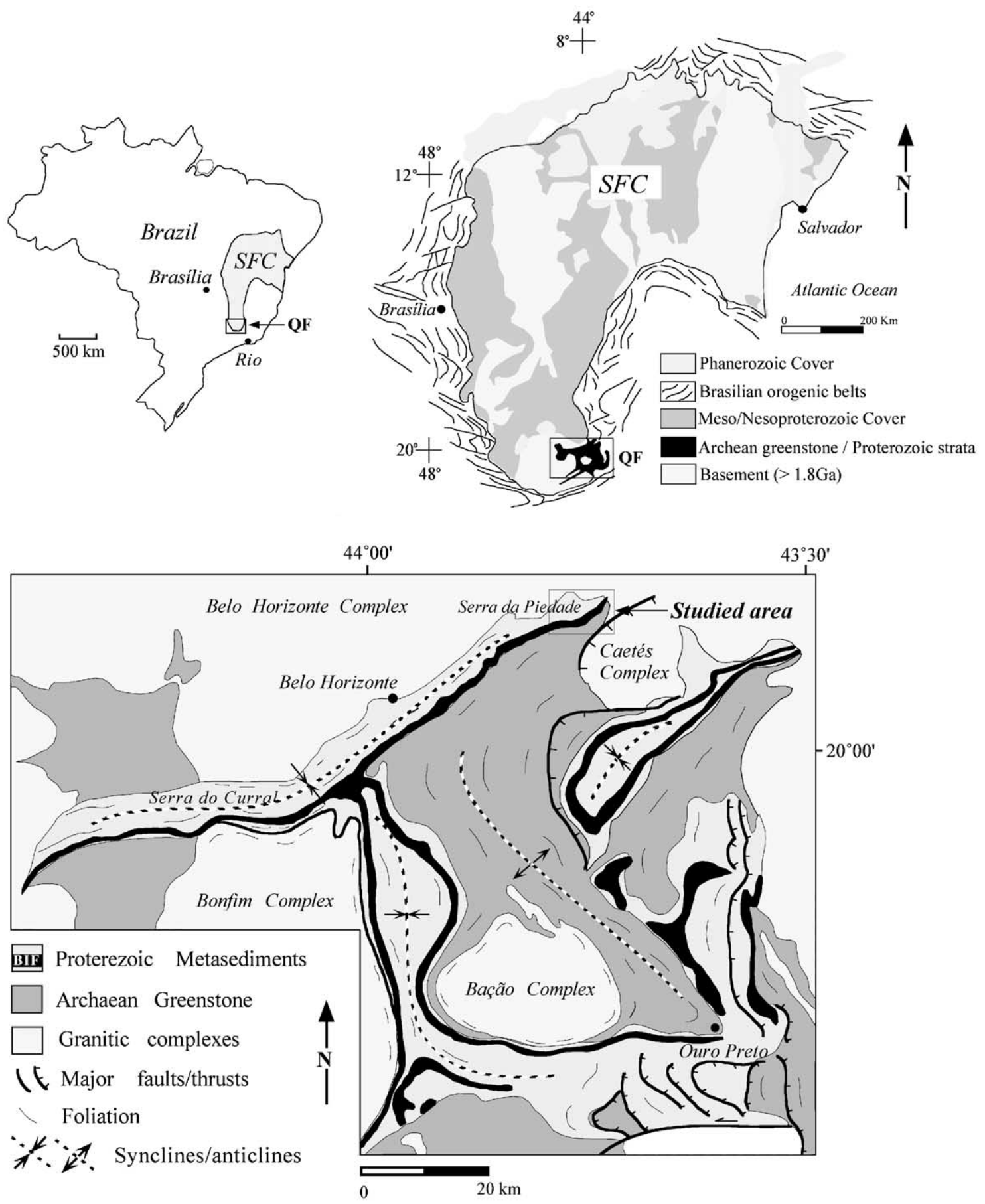

Fig. 1. Simplified geological map of the Quadrilátero Ferrífero granite-greenstone terrane in the southern margin of the São Francisco Craton (SFC). Location of the studied area in the northernmost tip of the Serra da Piedade Syncline is indicated. 
the 0.8-0.6 Ga Brasiliano Orogeny (Chemale et al., 1994; Alkmim and Marshak, 1998).

A static recrystallization event, whose age has not been determined yet, is responsible for the pervasive annealing of quartz aggregates in the Quadrilátero Ferrifero metavolcanic-sedimentary rocks. This is clearly seen in domains close to granitic-migmatitic-gneissic domes where mineral assemblage, in metapelitic parent country rocks, such as biotite, garnet, staurolite and andaluzite, indicates high temperature metamorphic conditions. This static grain growth has erased the syndeformational microstructures [e.g. undulose extinction, subgrains, oblique grain shape fabrics] and produced equant polygonal aggregates with abundant $120^{\circ}$ triple junctions in several domains of the Quadrilátero Ferrífero. Some domains, as for example the Serra da Piedade syncline, were preserved from being extensively recrystallized by the annealing process. It contains tectonites with preserved grain scale deformational structures and a pervasive grain shape fabric (GSF). The GSF is oblique to the axial trace of the microfold, which happens to be parallel to the compositional layering, since the folds are transposed. These rocks, therefore, are used in this study for investigation of the operating deformation mechanisms during isoclinal folding and transposition of quartz layers on a centimeter-millimeter scale and at low metamorphic grade conditions.

\section{Hand-specimen scale structures}

The specimens investigated in this study are $L-S$ tectonites. The samples show a prominent compositional banding from millimeter to centimeter scale defined by layers with different proportions of hematite and quartz. These bands define the main rock foliation and are composed of variably grained (dominantly fine-grained) recrystallized quartz-hematite aggregates. The compositional bands exhibit an anastomosing contour and are better described as elongated lenses on a centimeter scale, although it is not rare to find domains of regular alternating planar bands that extend for a few decimeters. The thickness of individual layers varies from several millimeters to a few centimeters. The typical layer length is in an order of $5-10 \mathrm{~cm}$. The contact between layers is generally sharp. A pervasive dip-slip, or slightly oblique, mineral stretching lineation, related to the $\mathrm{D}_{1}$ deformation, is defined by the morphological alignment of elongated hematite grains on the foliation plane.

The presence of isoclinal folded pure quartz layers is common in hand samples as well as in thin sections. Isoclinal folds are " $S$ "- or " $Z$ "-shaped depending on the view direction but, in a same section, the great majority of folds show a consistent geometry. The sense of vergence of the microfolds and the obliquity of axial planes with respect to the flow plane are consistent with the sinistral sense of shear (Figs. 2 and $3)$. These folds are typically asymmetrical where the inverted limbs are thinner and shorter than the normal limbs. In the hinge zone, layers are thicker than in the normal limbs. In the tectonites selected for this study, different stages of folding and transposition of the quartz-rich layers are preserved. In some samples, it is possible to recognize some unfolded or weakly folded quartz-rich layers. In others, isoclinal folds with preserved inverted limbs dominate. Centimeter/millimeter-sized, rootless isoclinal folds occur in the most sheared domains. Overall, the development of abundant isoclinal folds with axial planes parallel to the bulk shear plane, and sometimes with disrupted inverted limbs, is the most prominent feature in hand samples of these tectonites. We have analyzed several folded quartz layers and the $c$-axis patterns and we selected one representative microfold to document the several phenomena presented in this work. In the following sections, the microstructures from different parts of these folds are described through observation by optical and scanning electron microscopy (SEM), digital image analysis and measurement of quartz $c$ axis orientation with a five-axes universal stage.

\section{Microstructure and $c$-axis fabrics}

\subsection{Reference framework and general description}

Determination of finite strain ellipses in the Quadrilátero Ferrífero synclines (Hippertt and Davis, 2000) has revealed that the $X Y$-plane of the finite strain ellipsoid generally corresponds to the compositional layering of folded layered rocks where the $X$-axis is generally perpendicular to the syncline axis, the $Z$-axis 


\section{Serra da Piedade Syncline}

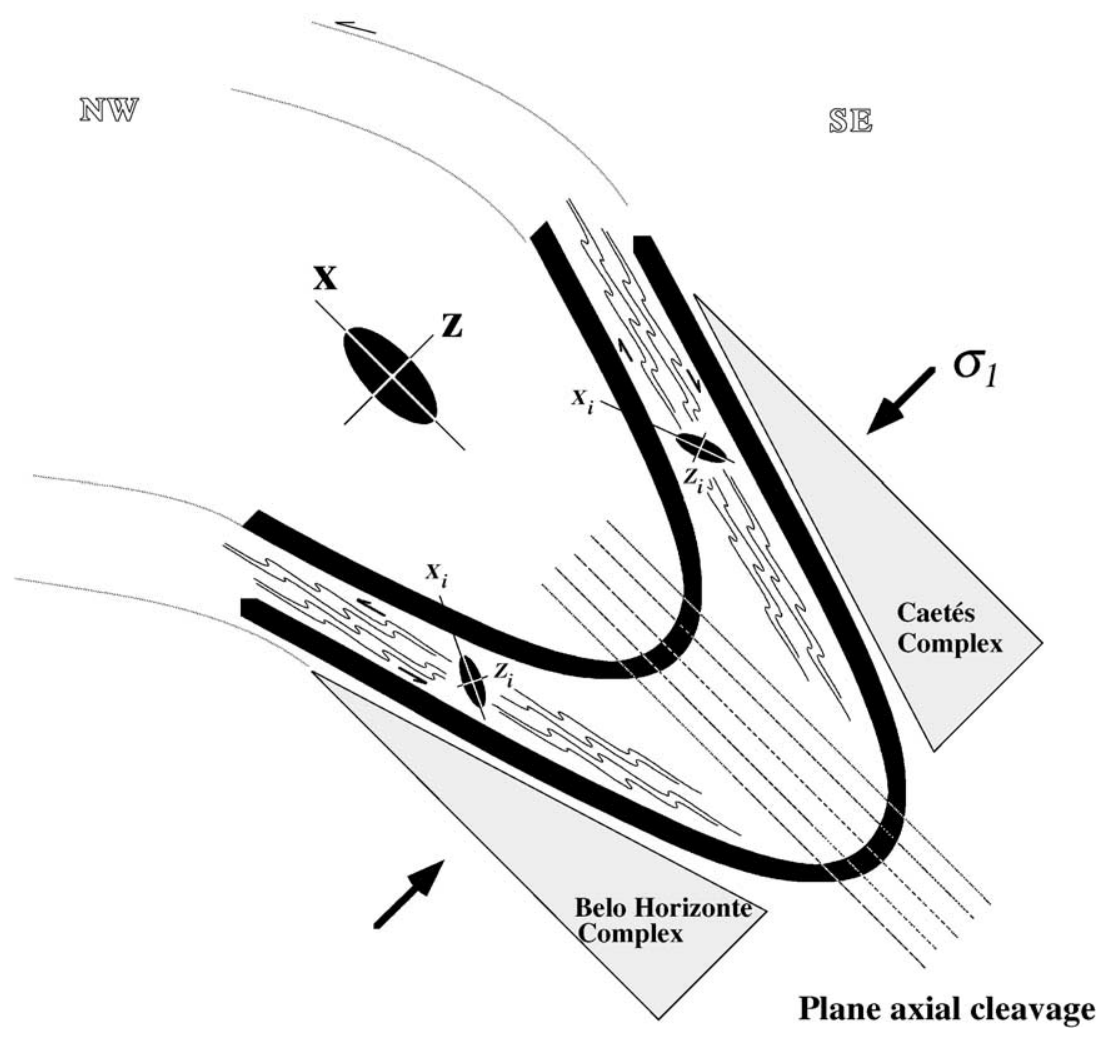

Fig. 2. Idealized cross-section of the Serra da Piedade Syncline showing the geometry of isoclinal folds with opposite vergences in each syncline limb. Orientation of the regional $X Z$ finite strain ellipse, the local $X_{i} Z_{i}$ incremental strain ellipses in each syncline limb, and the inferred maximum compressive regional stress $\left(\sigma_{1}\right)$ are indicated.

is perpendicular to the main foliation and the $Y$-axis is parallel to the syncline axis. In addition, the Serra da Piedade tectonites contain a pervasive GSF that is $30-55^{\circ}$ oblique to the main foliation, but shows opposite asymmetries in each syncline limb. Oblique GSFs (cf. Brunel, 1980; Burg, 1986) have been shown to be continuously reset during progressive noncoaxial deformation (Dell'Angelo and Tullis, 1989) and are therefore considered to represent the $X_{i} Y_{i^{-}}$ plane of instantaneous strain (Lister and Snoke, 1984). We assume this interpretation in this study, such that the inferred instantaneous strain ellipsoid in the Serra da Piedade tectonites is rotated between $30^{\circ}$ and $55^{\circ}$ around the $Y$-axis of finite strain. This situation is consistent with bedding-parallel shear related to flexural slip during syncline closure, and with the opposite shear senses between limbs as inferred from the asymmetric isoclinal folds geometry (Fig. 2). Thin sections were cut perpendicular to the bulk foliation (the compositional banding) and parallel to the mineral stretching lineation, such that they are assumed to be parallel to both the $X Z$-plane of finite strain and the $X_{i} Z_{i}$-plane of instantaneous strain. The rock slices used for thin section preparation were subsequently fractured, and fragments representative of the different fold domains were selected for observation under SEM.

On the optical microscope, $X Z$ thin sections of the tectonites display a well-developed banding composed by alternating hematite-rich and quartz-rich layers. Hematite-rich layers consist of variable proportions of hematite platelets (up to $60 \%$ in volume) 

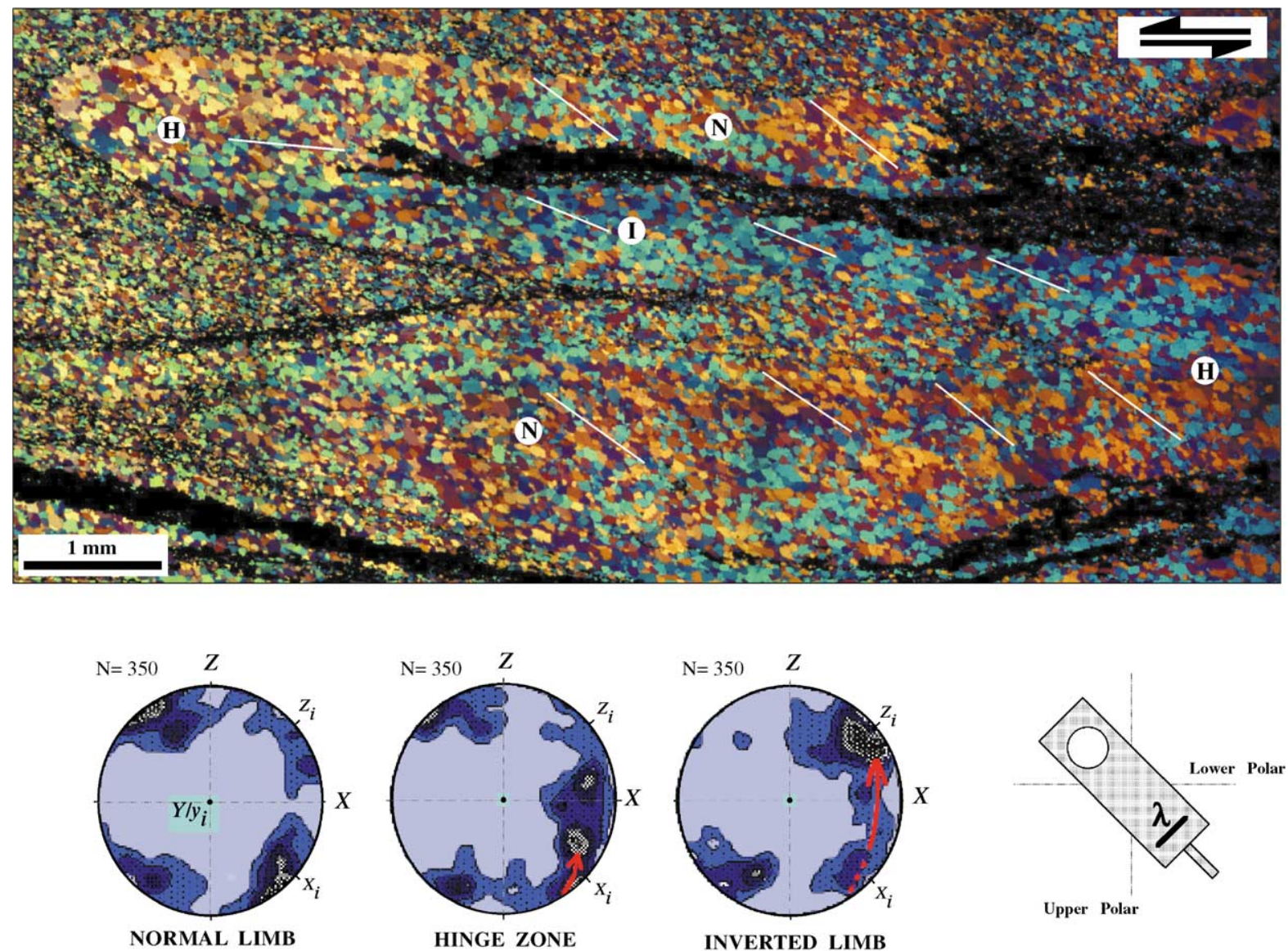

Fig. 3. Photomicrograph of the isoclinal quartz microfold investigated in this study (crossed polars and gypsum plate inserted, $\lambda=550 \mathrm{~nm}$ ). The strong contrast in $c$-axis orientation between normal limbs $(\mathrm{N})$ with dominant yellow grains, hinge zones $(\mathrm{H})$ and the short inverted limb $(\mathrm{I})$ with dominant blue grains, is clear. White lines indicate the grain shape orientation all through the fold. $c$-Axis fabrics determined with the universal stage in the different fold domains are also shown. The red arrow indicates the trajectory of the $c$-axis fabric maximum during progressive inversion of the short limb. Orientation of the finite and incremental strain axes is indicated. Lower hemisphere equal area projection, contour intervals of $1 \%, 2 \%, 3 \%, 4 \%$ and $5 \%$ per $1 \%$ area.

and quartz grains. In these layers, quartz average grain size decreases (from 110 to $30 \mu \mathrm{m}$ ) as the hematite content of the layer increases. Quartz-rich layers (focused on in this study) vary from a nearly pure quartz composition up to a hematite content about $20 \%$. Their average quartz grain size $(70-150 \mu \mathrm{m})$ is larger than in the hematite-rich layers. The microstructure and $c$-axis fabrics of normal limbs, inverted limb and hinge zones of a selected isoclinal fold modifying a quartz-rich layer (Figs. 3 and 4) are described in the next sections. Corresponding threedimensional grain boundary morphologies as observed by SEM in the different fold domains are shown in Fig. 4. Grain measurements, grain boundary maps and auto-correlation figures were made with the NIH Image (NIH Image (for Macintosh), National Institute of Health, 1999).

\subsection{Normal limbs}

In the normal limbs, tabular quartz grains dominate (average $X Z$ aspect ratio $\approx 2.05$ ). Average grain size calculated as diameter of the circle of same area $(D)$ is $100 \mu \mathrm{m}$. A strong GSF is defined by the longest and straight boundaries of tabular grains (average longest dimension $\approx 135 \mu \mathrm{m}$ ). This planar fabric is $35-55^{\circ}$ 

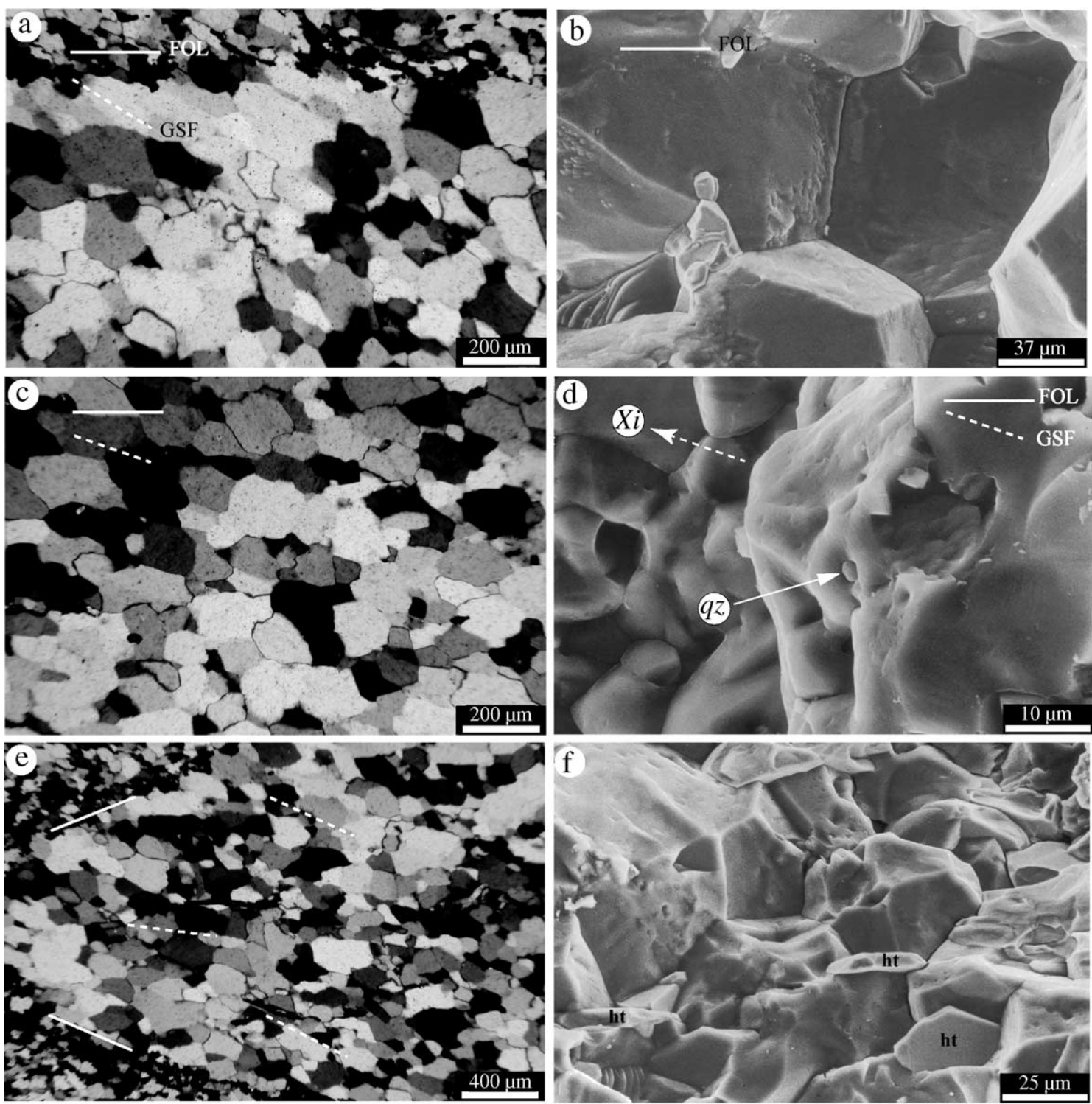

Fig. 4. Optical (cross polarizers) and SEM photographs, left and right columns, respectively, of different fold domains. (a) Normal limb microstructures. The compositional banding foliation (FOL) is marked by a continuous line whereas the oblique grain shape foliation (GSF) is done by a dashed line. The GSF, defined by the longest and straight boundaries of tabular grains, is $35-55^{\circ}$ (average $46^{\circ}$ ) oblique to the foliation plane. (b) Normal limb microstructures showing polyhedral grains with relatively planar grain boundaries and an incipient intergranular porosity. (c) Optical quartz grain microstructures in the inverted limb. The GSF has the same asymmetry as in normal limbs but with a smaller angle $\left(30-45^{\circ}\right.$; average $\approx 37^{\circ}$ ) to the compositional layering. Grain boundaries parallel to the GSF (perpendicular to $Z_{i}$-axis) tend to be more regular and flatter. (d) Inverted limb microstructures showing very irregular grain boundaries and a noticeable intergranular porosity. A grain protrusion parallel to $X_{i}$ and a flat boundary perpendicular to $Z_{i}$ are indicated. Small quartz grains (qz) occur within some intergranular pores. (e) Optical microstructures in the hinge zone. Fold envelope is marked by continuous lines whereas internal GSF is done by dashed lines. Note that in the internal domains of the fold hinge, GSF is approximately parallel the fold axial plane. (f) Hinge zone microstructures showing more curved, irregular grain boundaries and preferred orientation of hematite platy grains (ht). 
(average $46^{\circ}$ ) oblique to the axial trace of the microfold, which is parallel to the composition layering. Its asymmetry is consistent with the inferred sinistral shear sense (Figs. 3 and 4a). Grains with more curved outlines commonly protrude into the neighbor grains. Some indentations are as large as half diameter of the adjacent grain. More curved outlines occur predominantly at boundaries normal to the direction of the instantaneous strain axis $X_{i}$. Many grains exhibit undulose extinction, and some larger grains show preserved subgrains which are generally elongated parallel to the oblique GSF. These subgrains are mostly homogeneous in size and slightly smaller (average longest dimension $\approx 120 \mu \mathrm{m}$ ) than the recrystallized grains. Some quartz grains show inclusions of small hematite platelets oriented parallel to the main foliation and/or parallel to the oblique GSF. Most of these inclusions concentrate close to the grain boundaries.

SEM observation revealed varied grain boundary morphologies and pore geometries. Most grains are polyhedrons with planar grain boundaries that are variably rough in a scale of a few micrometers (Fig. 4b). The characteristic set of microstructures seen on the grain boundaries depends on the nature of the interfaces (if quartz-quartz or quartz-hematite) as well as on the orientation with respect to the strain axes. Phase boundaries quartz-hematite, which are parallel to the main foliation (i.e. perpendicular to the $Z$-axis) or to the GSF (i.e. perpendicular to the $Z_{i^{-}}$ axis), are more regular and pore-free. Quartz-quartz grain boundaries oriented at high angles to $Z$ - or $Z_{i^{-}}$ axes are flatter than those in other orientations but different from the interphase boundaries, there are some isolated pores on these boundaries. Grain boundaries perpendicular to the $X_{i^{-}}$and $Y_{i}$-axes are more irregular and/or rounded. Isolated pores are common in these interfaces and display well-defined shapes with crystallographically controlled faceted sides (inverted pyramids and triangular geometries). There is no evidence for pervasive pore connectivity, such that the overall microstructure in the normal limbs can be visualized as a low fluid volume, dry crystal-fluid system (cf. Laporte and Watson, 1991).

In all folded layers, quartz $c$-axis fabrics in the normal limbs (Fig. 3) consist of a single maximum that is $35-40^{\circ}$ oblique to the main foliation pole (i.e. the $Z$-axis), with a synthetic asymmetry relative to the inferred bedding-parallel shear sense. This maximum is asymmetrically distributed around the $X_{i}$-axis and has an opening angle of around $20^{\circ}$. A subordinate concentration of $c$-axes appears around the GSF pole ( $Z_{i}$-axis).

\subsection{Inverted limb}

Quartz grains in the inverted limb are also predominantly elongated, but display more varied shapes than in normal limbs. Grain boundaries are more serrate (sinuosity factor 1.44 vs. 1.35 in normal limbs) principally those oriented at high angles to the $X_{i}$-axis. Grain boundaries parallel to the GSF and, therefore, perpendicular to the direction of maximum incremental shortening $\left(Z_{i}\right.$-axis) tend to be more regular and flatter, particularly when in contact with platy hematite grains. On the other hand, grain boundaries facing the $X_{i}$-axis (i.e. grain boundaries perpendicular to the GSF) tend to be more irregular. Small inclusions of hematite are concentrated along these irregular boundaries facing $X_{i}$.

The preferred orientation of the longest morphological axes of the grains defines an oblique GSF; this, however, is poorer than the GSF in the normal limbs. This GSF shows the same asymmetry as in normal limbs but with a smaller angle $\left(30-45^{\circ}\right.$; average $\approx 37^{\circ}$ ) to the compositional layering (parallel to the axial trace of the microfold). Grain aspect ratio is larger (average $\approx 2.11$ ), but grain size is smaller than in the normal limbs (average $D \approx 95$ $\mu \mathrm{m})$. The characteristic microstructure consists of an aggregate of dominant elongated grains with lobate/ serrate grain boundaries, and devoid of optically visible undulose extinction and subgrains. In some parts of the inverted limb, aggregates of polygonal equant grains occur. These equant grains are smaller $(60-90 \mu \mathrm{m})$ than the elongated grains and are apparently devoid of optically observable crystalplastic deformational microstructures.

SEM observation revealed abundant intergranular pores in the inverted limb (Fig. 4c), noticeably on grain boundaries that protrude along the $X_{i}$-axis. Most grain boundaries show a typical "valley and ridge" morphology (cf. Cox and Paterson, 1991). Larger irregular-shaped pores are generally connected through grain boundaries and grain edges, defining a wetted crystal-fluid microstructure in these domains 
(cf. Lee et al., 1991). Some pores with very irregular morphologies developed an appearance of "caves". Pores show a wide range of sizes $(0.5-15 \mu \mathrm{m})$ and depths $(0.2-5 \mu \mathrm{m})$. Small euhedral crystals of quartz and/or hematite are commonly present within irregular-shaped pores located on grain boundaries facing $X_{i}$. Similar to the normal limbs, pores are rare at the interphase boundaries oriented at high angles to $Z$ or $Z_{i}$. Quartz-quartz boundaries with this orientation also tend to be flatter and pore-free on a micrometer scale (Fig. 4c). Faceted isolated pores occur on grain boundaries facing the $Y / Y_{i}$-axis. No inclusions of quartz or hematite were observed in these pores.

In contrast to the normal limbs, $c$-axes in the inverted limb of all folded quartz layers analyzed are distributed around the $Z_{i}$-axis, i.e. in an orientation perpendicular to the GSF. The $c$-axis maximum is more scattered than in the normal limbs and has an opening angle of $25-30^{\circ}$. A secondary concentration of $c$-axes occurs around the $X_{i}$-axis.

\subsection{Hinge zone}

Microstructure in the hinge zones is a transition between the limbs, where most parameters show an intermediate value between those found in normal and inverted limbs (Table 1). An exception is the grain size which is smaller (average $D \approx 91 \mu \mathrm{m}$ ) than in the limb domains. The average $X Z$ aspect ratio (2.06) is about the same as in the normal limb. The GSF is less developed and displays a more variable orientation range $\left(15-45^{\circ}\right.$; average $\left.\approx 40^{\circ}\right)$ than in the limbs, but the same asymmetry relative to the compositional layering. In internal domains of the hinge zones, the GSF is sometimes almost parallel to the fold axial plane. Grains are generally devoid of optically observable crystal-plastic deformational microstructures.
The hinge zones are some $10-20 \%$ enriched in hematite relative to the limbs, making quartz grains to be commonly pinned by hematite flakes. These hematite flakes show a preferred morphological orientation parallel to the fold axial plane.

SEM observation of the hinge zones reveals an intermediate pattern between the curved, rough and porous quartz grain boundary morphologies observed in the inverted short limb, and the relatively flatter and "dry" grain boundaries observed in the normal limbs.

$c$-Axis fabrics determined in the hinge zones of all folded quartz layers also reflect this transition between the two limbs. $c$-Axes are scattered around the $X$-axis with a maximum in an intermediate position between the $X$ - and $X_{i}$-axes. Secondary concentrations occur close to the $X_{i^{-}}$and $Z$-axes, i.e. the same preferred orientations found in normal and inverted limbs, respectively.

\section{Data analysis and 2-D grain size distributions}

By using the NIH image analysis software, we have measured grain perimeter $(L)$, grain area $(A)$, major and minor grain dimensions and shape orientation of about 2500 grains in the different fold domains (Table 1). From these measurements, we have calculated the average aspect ratio, the diameter $(D)$ and circumference $(C)$ of the circle having the same area as the grain, and the sinuosity factor $(L / C)$. This sinuosity factor indicates the degree of serration of a grain outline by comparing its perimeter with the circumference of the circle of same area.

In order to obtain the full 2-D size distribution, grain contours were performed manually using Adobe ${ }^{\circledR}$ graphic software package from optical micrographs taken under crossed polarizers. We used the public

Table 1

Statistics of measured and calculated microstructural parameters in the different fold domains

\begin{tabular}{|c|c|c|c|c|c|c|c|c|c|}
\hline & \multicolumn{3}{|c|}{ Normal limb } & \multicolumn{3}{|c|}{ Inverted limb } & \multicolumn{3}{|c|}{ Hinge zone } \\
\hline & Mean & Variance & Kurtosis & Mean & Variance & Kurtosis & Mean & Variance & Kurtosis \\
\hline Grain size $(\mu \mathrm{m})$ & 99.7 & (2430) & (1.49) & 95.9 & (3008) & $(4.46)$ & 91.7 & $(2285)$ & $(0.68)$ \\
\hline Sinuosity $(L / C)$ & 1.35 & $(0.06)$ & (1.98) & 1.44 & $(0.08)$ & (3.34) & 1.40 & $(0.05)$ & $(1.56)$ \\
\hline Aspect ratio & 2.05 & $(0.75)$ & (6.59) & 2.11 & $(0.81)$ & (14.7) & 2.06 & $(0.78)$ & $(25.4)$ \\
\hline GSF orientation & $46^{\circ}$ & (2539) & $(-0.11)$ & $37^{\circ}$ & (2968) & $(-0.09)$ & $40^{\circ}$ & (2324) & $(0.75)$ \\
\hline$N$ & 1101 & & & 837 & & & 567 & & \\
\hline
\end{tabular}


domain software NIH image 1.62 to extract quartz grain boundaries by appropriate gray level slicing. Using the 'Analyze' menu, the bitmaps were evaluated. The list of measurements was then transferred to the Kaleidagraph ${ }^{\circledR}$ spreadsheet program. The grain crosssectional areas were given in pixels. They were scaled and converted to $\mu \mathrm{m}^{2}$. To obtain the radii of the equivalent circles $(r)$, with the same area as the crosssectional grain shapes, the areas were divided by $\pi$ and then the square root was taken.

$d=2 r=2(\operatorname{area} / \pi)^{1 / 2}=1.128 \operatorname{area}^{1 / 2}$

where $d=$ diameter, $r=$ radius of the equivalent circles, area $=$ measured area of the cross-sectional grain shape.

\section{Discussion}

\subsection{Inferring deformation processes from micro- structures}

The unimodal grain size distribution and the absence of identifiable relic quartz grains (porphyroclasts) indicate that these quartz-rich layers have been completely recrystallized during progressive folding. Most grains are devoid of optically visible deformational microstructures but, in the normal fold limbs, some exhibit subtle undulose extinction bands and elongated subgrains (parallel to GSF) that are only slightly smaller than the recrystallized grains. These features, in addition to the development of oblique GSF, $c$-axis preferred orientation, and the common presence of grain boundary protrusions with a large wavelength are all, in principle, characteristic of dislocation creep regime accomplished by rotation recrystallization and grain boundary migration (Drury and Urai, 1990; Hirth and Tullis, 1992). Also, the large number of oriented hematite inclusions, which commonly "pin" the quartz grain boundaries, suggest that grain boundary migration played an important role on the microstructure development in all domains of the folded quartz aggregate.

Although the presence of GSF and deformational microstructures at individual grain scale such as undulose extinction and subgrains are undoubtedly related to crystal-plastic deformation, grain boundary migration itself and the development of $c$-axis fabrics are not (den Brok, 1992), as these features have been shown to commonly develop during fluid-assisted solution-precipitation deformation as well (e.g. Takeshita and Hara, 1998). Moreover, in low to medium metamorphic grade conditions, crystal-plastic deformation and solution-precipitation creep can be intimately associated or even coexisting processes at a microscale (e.g. Hippertt, 1994; Lagoeiro, 1999; Mamtani et al., 1999), such that the operative deformation mechanisms cannot be inferred on basis of such features only (den Brok, 1992).

Three-dimensional SEM observation of grain boundary morphologies in different fold domains provided additional information to assess the role of these different deformation processes. In normal limbs grain boundaries are relatively straight and show incipient pore development. In inverted limbs, grains are devoid of optically observable undulose bands and subgrains and have more curved and rougher boundaries than those present in the normal limbs and hinge zones, particularly those facing the $X_{i}$-axis. SEM micrographs in inverted limbs display grain boundaries with a large number of irregular-shaped pores on a micrometer scale, which are connected and commonly display a "corroded" aspect. These features are diagnostic of a thermodynamically unstable, wetted crystal-fluid microstructure characterized by the presence of dynamic (mobile) crystal-fluid interfaces (Watson and Brenan, 1987). Such a discernible porosity reflects the presence of a high volumetric, intergranular fluid phase which may commonly enable mass transfer between dissolution and deposition sites through connected fluid-filled pores (e.g. Watson and Lupulescu, 1993). Euhedral quartz and hematite crystals are found within these irregular-shaped pores confirming these pores were originally fluid-filled.

Another difference consists in that elongated quartz grains in inverted limbs show a noticeable contrast between flat boundaries oriented perpendicular to the maximum incremental shortening direction $\left(Z_{i}\right.$-axis) and more porous and protruding boundaries facing the $X_{i}$-axis. These features accord well with the mechanism of pressure solution where quartz dissolution occurs on grain boundaries perpendicular to the maximum shortening direction, in concert with precipitation on boundaries facing the maximum elongation direction. This process is consistent with the larger average aspect ratio measured in the inverted limbs, 
and the observed concentration of hematite inclusions in domains adjacent to lobate boundaries facing $X_{i}$. Where the isoclinal folds are transposed, the disruption always occurs in inverted limbs, and thinning of short limbs is commonly observed in isoclinal folds with assorted degrees of fold closure. These features suggest continued strain localization in short limbs during progressive folding and limb inversion, which

a)
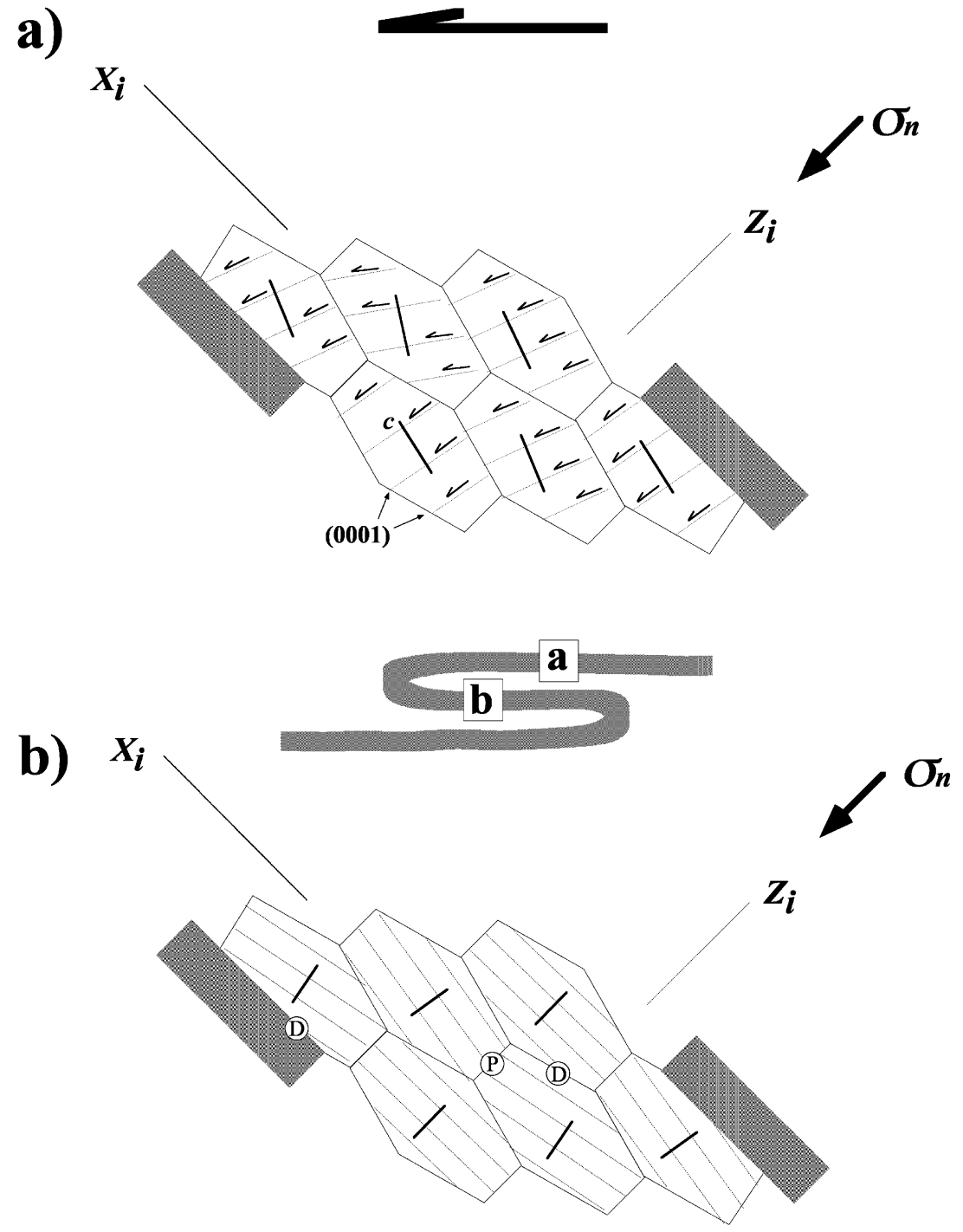

Fig. 5. (a) Sketch illustrating the suitability to basal $\langle a\rangle$ glide in grain aggregates of normal limbs. (b) Sketch illustrating the situation in inverted limbs, where $c$-axes lay at low angles to $Z_{i}$ and the maximum compressive normal stress $\left(\sigma_{\mathrm{n}}\right)$. Potential sites for dissolution (D) and precipitation (P) are indicated. Black objects denote oriented hematite grains. 
cannot be explained exclusively via operation crystalplastic processes, as discussed in the next section.

\subsection{Significance of c-axis fabrics}

The quartz $c$-axis preferred orientation is readily visualized by insertion of the gypsum plate (Fig. 3). In normal limbs, $c$-axes are asymmetrically distributed around the $Z$-axis; the maximum concentration rotated some $35^{\circ}$ from the $Z$-axis, synthetically with the shear sense inferred from the isoclinal fold geometry. In non-coaxial deformation at low metamorphic grade, such an asymmetric concentration of $c$-axes around the bulk shear plane pole is considered as diagnostic of crystal-plastic deformation through dominant basal $\langle a\rangle$ slip (e.g. Schmid and Casey, 1986; Law, 1990).

Contrary to the above, $c$-axis fabrics in the inverted limbs concentrate around the direction of maximum instantaneous shortening $\left(Z_{i}\right.$-axis), i.e. in an orientation perpendicular to the GSF and approximately at $90^{\circ}$ to the orientation of $c$-axes in the normal limbs. This orientation may have been produced as a result of $c$-axes rotation (cf. Carreras et al., 1977) during progressive inversion of short limbs up to an orientation where the quartz basal planes (0001) become oriented perpendicular to the maximum shortening direction. Grains with this orientation correspond to those of 'hard orientation' for basal $\langle a\rangle$ slip [i.e. zero or low resolved shear stress (RSS) on basal planes] and are, therefore, not favorably oriented for dislocation glide. We interpret that quartz basal planes were "blocked" in this low RSS orientation, because this orientation was maintained even in $180^{\circ}$ inverted short limbs (as in Fig. 3), such that a $180^{\circ}$ rotation of the short limb corresponded to only $90^{\circ}$ rotation of the $c$-axis fabric. Thus, considering that dislocation glide through basal $\langle a\rangle$ slip was the main mechanism for the development of crystallographic preferred orientation in normal limbs, and that grains in inverted limbs are not favorably oriented for that, a different deformation process should have operated in inverted limbs to accommodate progressive strain during isoclinal folding/transposition.

\subsection{Operation of dissolution-precipitation creep in inverted limbs}

The quartz and hematite grains observed within pores on quartz grain boundaries facing $X_{i}$ provide an indication that precipitation did occur in inverted limbs. Therefore, corresponding dissolution sites for quartz (and for hematite; e.g. Lagoeiro, 1998) are expected to exist in these rocks. The key fact to elucidate this point is that quartz $c$-axes in inverted limbs were brought to an orientation that is hard for dislocation glide but easier for the dissolution. Theoretical predictions (Tullis, 1989), observation of naturally deformed quartz (e.g. Hicks et al., 1986; Hippertt, 1994; Becker, 1995) and experimental studies (e.g. den Brok, 1996) have demonstrated that dissolution of quartz grains depends on the crystallographic orientation as well as on the presence of a second phase, particularly platy minerals (e.g. Houseknecht, 1988), indicating that quartz is highly anisotropic for dissolution. The characteristics of this anisotropic dissolution are, however, still uncertain. Becker (1995) and den Brok (1996) concluded that "grains with $c$-axes oriented at about $50^{\circ}$ to $Z$ manifest the highest degree of pressure solution". Other studies, however, showed that quartz is more easily dissolved when, (1) its basal planes are perpendicular to the maximum shortening direction and, (2) when a basal grain boundary is in contact with a highly anisotropic, platy mineral grain such as phyllosilicates or hematite (Hicks et al., 1986; Tullis, 1989; Hippertt, 1994; Lagoeiro, 1999). In inverted limbs of the studied isoclinal folds, these two conditions were met. Dissolution of quartz grains has probably occurred in inverted limbs as a consequence of $c$-axes become oriented parallel to the maximum incremental shortening and also because, in this orientation, platy hematite crystals which are oriented

Fig. 6. (a) Idealized plot of deformation vs. time during progressive isoclinal folding. After folding begins, strain is increasingly concentrated in short limbs, leading to transposition through short limb disruption. Numbers 1-5 correspond to the microstructures shown in (c). (b) Suggested deformation partitioning between crystal-plasticity (CP) and solution-precipitation creep (SP) in short limbs. Participation of solutionprecipitation creep increases after short limb inversion. (c) Microstructures and corresponding $c$-axis fabrics of stages $1-5$ as marked in (a). Arrows show the average $c$-axis trajectory in short limbs. 


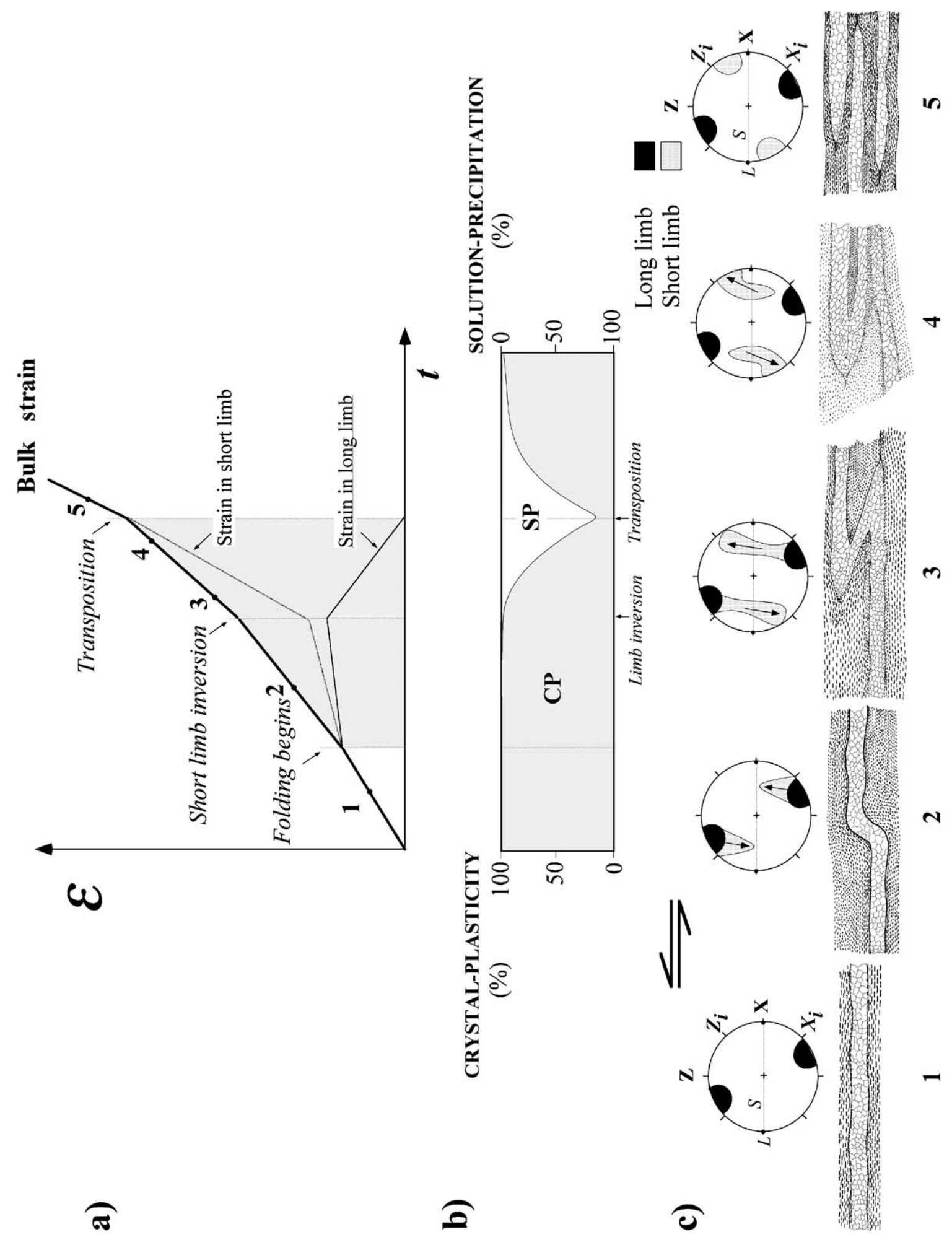


parallel to the GSF have their largest boundaries in contact with basal boundaries of quartz, a suitable situation for dissolution that did not occur in normal limbs (Fig. 5). Thus, grains were dissolved along their basal/sub-basal boundaries facing $Z_{i}$ and at least part of the dissolved silica was precipitated on grain boundaries facing $X_{i}$, as indicated by the concentration of hematite inclusions in these domains. The operation of this mechanism resulted in grains that are elongated parallel to $X_{i}$ and shortened parallel to $Z_{i}$, i.e. the same morphological preferred orientation present in the normal limbs. Thus, we interpret that grains in inverted limbs developed a GSF with the same obliquity as in the normal limbs, but through a different deformation process.

The interpretation above is consistent with observation of highly porous grain boundaries in inverted limbs, a feature that is commonly associated with dissolution-precipitation creep at low to mid metamorphic grade conditions (e.g. Watson and Brenan, 1987). The contrasting porosity between normal limbs and inverted limbs reflects an anisotropic fluid phase distribution during folding of these quartz layers. We suggest that after dissolution starting to operate in inverted limbs, porosity was generated and the intergranular fluid phase volume should have increased in these domains (and decreased in the normal limbs if no fluid was added to the system). The outcome was an enhanced deformation partitioning during progressive folding/transposition between crystal-plastic deformation in the relatively "dry" normal limbs, and fluid-assisted dissolution - precipitation creep in the "wet" inverted limbs (Fig. 6). One possibility for the mechanism of pore formation might involve the development of microcracks perpendicular to $X_{i}$. These microcracks might act as sinks where quartz is precipitated after undergoing pressure solution (den Brok, 1992). This might explain the concentration of pores and small grains found at grain boundaries normal to $X_{i}$. Nevertheless, the two processes, i.e. microcracking and pore formation on one hand, and solution-precipitation creep on the other, might proceed simultaneously and complement each other. These results and interpretations are consistent with the general principles involved with cleavage development during folding at low metamorphic grade, where crystal-plasticity is intimately associated with domainal dissolution-precipitation creep (e.g. Mam- tani et al., 1999), and commonly leads to foliation transposition through development of solution cleavages in stretched fold limbs.

\section{Conclusions}

The microstructure and $c$-axis preferred orientation of isoclinal folded quartz layers may reflect the operation of two distinct deformation processes in different domains of microscale folds. The GSF and $c$-axis fabrics in normal limbs are indicative of deformation through dislocation creep. In the inverted limbs the $c$-axis fabric is very contrasting ( $c$-axes parallel to $Z_{i}$ ) although the GSF has the same obliquity as in the normal limbs. Quartz grains in inverted limbs were brought to an orientation of low RSS on the (0001) basal planes, which prevented crystal-slip and enabled continued deformation through fluid-assisted dissolution-precipitation creep. Operation of dissolution-precipitation creep in inverted limbs has produced a similar GSF as in the normal limbs, but with a different $c$-axis preferred orientation.

An important implication of this deformation partitioning between crystal-plasticity and solution-transfer processes is that, in highly sheared and transposed layered quartz rocks, individual quartz layers may show alternating $c$-axis fabrics with opposite asymmetries. A composite $c$-axis fabric taken from several layers would show a misleading pattern with an orthogonal symmetry similar to those developed in coaxial deformation. However, GSF maintains a consistent orientation in all layers and will aid to identify rocks that have been pervasively folded/transposed during non-coaxial deformation.

\section{Acknowledgements}

We would like to express our gratitude to Andrea C. Ferreira, Lucas Fidelis Costa and Rafael Romano in the laboratory of microscopy and digital image analysis (MICROLAB) of the Department of Geology at Federal University of Ouro Preto. We thank Manish A. Mamtani and two anonymous reviewers for the constructive comments, which considerably improved the paper. We also thank Kip Hodges for the editorial handling. Partial financial support for this work was 
provided by a research grant from the Brazilian National Research Council (CNPq, process 523688/ 96-2).

\section{References}

Alkmim, F., Marshak, S., 1998. Transamazonian orogeny in the southern São Francisco Craton Region, Minas Gerais, Brazil: evidence for Paleoproterozoic collision and collapse in the Quadrilátero Ferrífero. Precambrian Research 90, 29-58.

Becker, A., 1995. Quartz pressure solution: influence of crystallographic orientation. Journal of Structural Geology 17, $1395-1405$

Brunel, M., 1980. Quartz fabrics in shear zone mylonites: evidence for a major imprint due to late strain increments. Tectonophysics 64, 33-44.

Burg, J.-P., 1986. Quartz shape fabric variations and $c$-axis fabrics in a ribbon mylonite: arguments for an oscillating foliation. Journal of Structural Geology 8, 123-131.

Carreras, J., Estrada, A., White, S., 1977. The effects of folding on the $c$-axis fabrics of a quartz-mylonite. Tectonophysics 39, 3-24.

Chemale, F., Rosiere, C., Endo, I., 1994. The tectonic evolution of the Quadrilátero Ferrífero, Minas Gerais, Brazil. Precambrian Research 65, 25-54.

Cox, S., Paterson, M., 1991. Experimental dissolution-precipitation creep in quartz aggregates at high temperatures. Geophysical Research Letters 18, 1401-1404.

Dell'Angelo, L.N., Tullis, J., 1989. Fabric development ub experimentally sheared quartzites. Tectonophysics $169,1-21$.

den Brok, B., 1992. An experimental investigation into the effect of water on the flow of quartzite. Geologica Ultraiectina 95, 1-178.

den Brok, B., 1996. The effect of crystallographic orientation on pressure solution in quartzite. Journal of Structural Geology 18, $859-860$.

Drury, M.R., Urai, J.L., 1990. Deformation-related recrystallization processes. Tectonophysics 172, 235-253.

FitzGerald, J.D., Stünitz, H., 1993. Deformation of granitoids at low metamorphic grade I: reactions and grain size reduction. Tectonophysics 221, 299-324.

Hicks, B., Applin, K., Houseknecht, D., 1986. Crystallographic influences on intergranular pressure solution in a quartzose sandstone. Journal of Sedimentary Petrology 56, 784-787.

Hippertt, J., 1994. Microstructures and $c$-axis fabrics indicative of quartz dissolution in sheared quartzites and phyllonites. Tectonophysics 229, 141-163.

Hippertt, J., Davis, B., 2000. Dome emplacement and formation of kilometre-scale synclines in a granite-greenstone terrain (Quadrilátero Ferrífero, southeastern Brazil). Precambrian Research 102, 99-121.

Hirth, G., Tullis, J., 1992. Dislocation creep regimes in quartz aggregates. Journal of Structural Geology 14, 145-159.

Hoefs, J., Muller, G., e Schuster, A.K., 1982. Polymetamorphic relations in iron ores from iron quadrangle Brazil: the correlation of oxygen isotope variations with deformation history. Contributions to Mineralogy and Petrology 79, 241-251.
Hongn, F., Hippertt, J.F., 2001. Quartz crystallographic and morphologic fabrics during folding/transposition in mylonites. Journal of Structural Geology 23, 81-92.

Houseknecht, D.W., 1988. Intergranular pressure solution in four quartzose sandstones. Journal of Sedimentary Petrology 58, $228-246$.

Lagoeiro, L., 1998. Transformation of magnetite to hematite and its influence on the dissolution of iron oxide minerals. Journal of Metamorphic Geology 16, 415-423.

Lagoeiro, L., 1999. Contrasting $c$-axis fabric patterns in layers of different proportion of quartz and iron oxides. In: Szpunar, J.A. (Ed.), Twelfth International Conference on Textures of Materials. National Research Council, Canada Proceedings, 2, $1528-1533$.

Laporte, D., Watson, E., 1991. Direct observation of near-equilibrium pore geometry in synthetic quartzite at $600-800{ }^{\circ} \mathrm{C}$ and $2-10.5$ kbar. Journal of Geology 99, 873-878.

Law, R.D., 1990. Crystallographic fabrics: a selective review of their applications to research in structural geology. In: Knipe, E.H., Rutter, E.H. (Eds.), Deformation mechanisms, rheology and tectonics. Special Publication - Geological Society 54, $335-3352$.

Lee, V., Mackwell, S., Brantley, S., 1991. The effect of fluid chemistry on wetting textures in Novaculite. Journal of Geophysical Research 96, 10023-10037.

Lister, G., Snoke, A., 1984. S-C mylonites. Journal of Structural Geology 6, 617-638.

Mamtani, M., Karanth, R., Greiling, R., 1999. Are crenulation cleavage zones mylonites on the microscale? Journal of Structural Geology 21, 711-718.

National Institute of Health, 1999. NIH Image 1.62, public domain image analysis software. http://rsb.info.nih.gov/nih-image/ download.html.

Robin, P.-Y., 1978. Pressure solution, a grain-to-grain contact. Geochimica et Cosmochimica Acta 42, 1383-1389.

Rutter, E.H., 1983. Pressure solution in nature, theory and experiment. Journal of the Geological Society (London) 140, 725-740.

Schmid, S.M., Casey, M., 1986. Complete fabric analysis of some commonly observed quartz $c$-axis patterns. In: Hobbs, B.E., Heard, H.C. (Eds.), Mineral and rock deformation: laboratory studies (Paterson volume). American Geophysical Union, Monograph Series 36, 263-286.

Shimizu, I., 1995. Kinetics of pressure solution creep in quartz: theoretical considerations. Tectonophysics 245, 121-134.

Stallard, A., Shelley, D., 1995. Quartz c-axes parallel to stretching directions in very low grade metamorphic rocks. Tectonophysics 249, 31-40.

Stünitz, H., 1991. Folding and shear deformation in quartzites, inferred from crystallographic preferred orientation and shape fabric. Journal of Structural Geology 13, 71-86.

Stünitz, H., 1993. Transition from fracturing to viscous flow in a naturally deformed metagabbro. In: Boland, J.N., FitzGerald, J.F. (Eds.), Defects and Processes in the Solid State: Geoscience Applications. Elsevier, Amsterdam, pp. 121-150.

Takeshita, T., Hara, I., 1998. c-Axis fabrics and microstructures in a recrystallized quartz vein deformed under fluid-rich greenschist conditions. Journal of Structural Geology 20, 417-431. 
Tanner, P., 1989. The flexural slip mechanism. Journal of Structural Geology 11, 635-655.

Tanner, P., 1992. Morphology and geometry of duplexes formed during flexural-slip folding. Journal of Structural Geology 14, $1173-1192$

Tullis, T., 1989. Development of preferred orientation due to anisotropic dissolution/growth rates during solution-transfer creep (abstract). Eos, American Geophysical Union 70, 457.
Watson, E.B., Brenan, J.M., 1987. Fluids in the lithosphere. 1. Experimentally determined characteristics of $\mathrm{CO}_{2}-\mathrm{H}_{2} \mathrm{O}$ fluids and their implications for fluid transport, host-rock physical properties, and fluid inclusion formation. Earth and Planetary Science Letters 85, 497-515.

Watson, E.B., Lupulescu, A., 1993. Aqueous fluid connectivity and chemical transport in clinopyroxene-rich rocks. Earth and Planetary Science Letters 117, 279-294. 